\title{
Car(e) to Share? A Mathematical Analysis of the Car-sharing Industry
}

\section{Executive Summary}

We live in an era of unprecedented mobility_-vehicles are much more affordable than they were at their inception in the early 20th century, and public transport provides an easy and economical means of travel for those without a personal vehicle. The latest trend in the transportation industry is that of car-sharing. Realizing that purchasing and owning a personal vehicle can be unnecessarily expensive, individuals are starting to turn to cheaper and more distributed means of paying for private vehicle transport.

In order to help illuminate various aspects of the car-sharing process, our team developed mathematical models that address some of the main factors influencing car-sharing companies' decisions. First, we developed a model that determines the proportion of drivers that fit into categories--low, medium, and high-for both hours driven per day and miles driven per day. We realized that much of the information regarding these two factors depended greatly on the amount of traffic in an area or city, which subsequently depended on the population density of that region. Hence, we created a function that gives the expected number of miles driven in a day based on the population density of the city or region and the number of hours driven in a day. We then placed a normal distribution around this expected average value and integrated a weighted cumulative distribution function of that distribution over time to get a table of proportions of drivers in each category. Next, we tested our model in two regions, New York City and Englewood Cliffs, a small suburban locale. Our model produced logical results in that it predicted a majority of cars moving shorter distances in New York City and a majority of cars moving longer distances in the less densely populated town of Englewood Cliffs.

We were also asked to create a model to rank four potential business plans for car-sharing companies in four different cities. We found an equation to model a "price" for the consumer that included both financial cost and opportunity cost, which represents a combination of time spent and the value of that time. We graphed the cost versus user salary for each of 4 different consumer scenarios to determine which potential business plan would be most beneficial given a user's salary and scenario. This user-benefit model incorporates the population density of a region to give the quantity of users for a car-sharing business in that region. We then calculated the company's revenue and cost per user for each business model and combined these calculations with the number of users in a region to get the expected profit. We applied this to the four cities and ranked them. This analysis would be highly beneficial to any car-sharing company wishing to expand to a new urban location.

Finally, we were asked to consider the effects of alternative energy vehicles and selfdriving vehicles on the car-sharing market. We altered our model from Part II to adjust for the changes in usage, cost, and revenue to show the effects of these future changes. Any company wishing to develop a car-sharing business should consider these insights and future changes in order to keep their service relevant in the fast-paced world of automobile technology. 


\section{Contents}

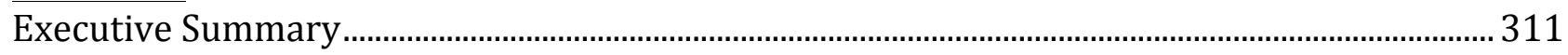

Restatement of the Problem............................................................................................................ 313

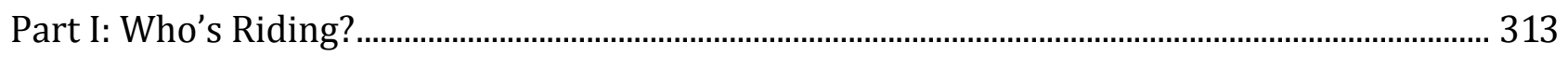

A. Restatement of the Problem ..................................................................................................... 313

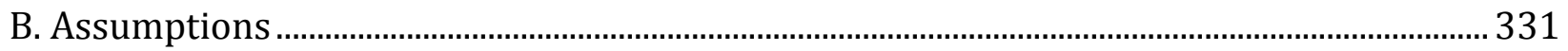

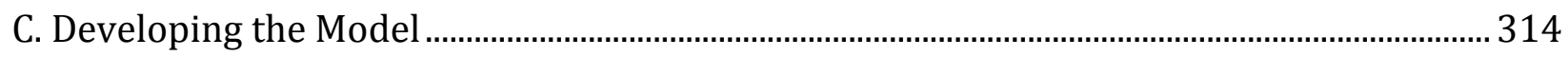

D. Validation of the Model................................................................................................................ 318

E. Results of the Model ....................................................................................................................... 319

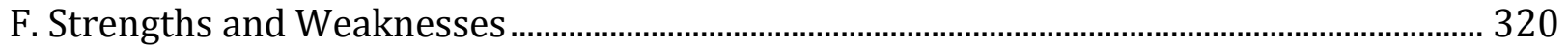

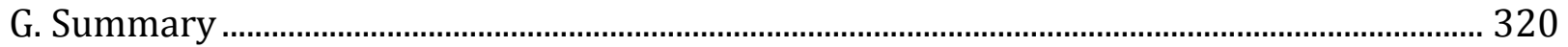

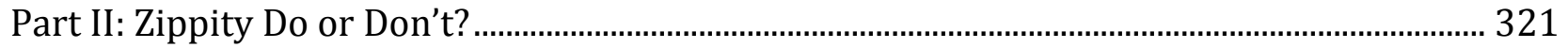

A. Restatement of the Problem ....................................................................................................... 321

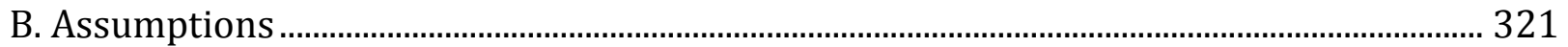

C. Modeling the Consumer ........................................................................................................... 322

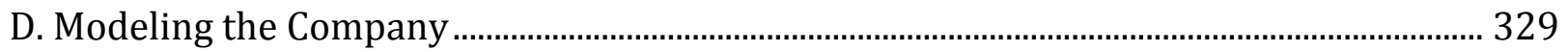

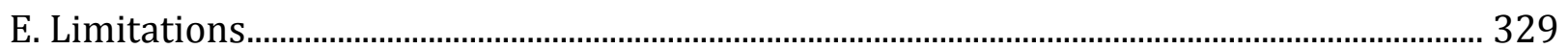

Part III: Road Map to the Future .......................................................................................... 329

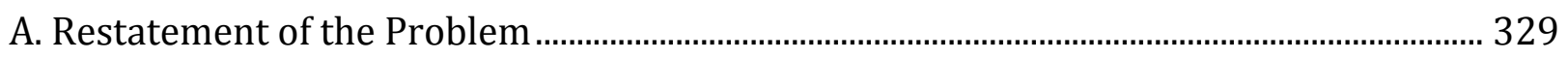

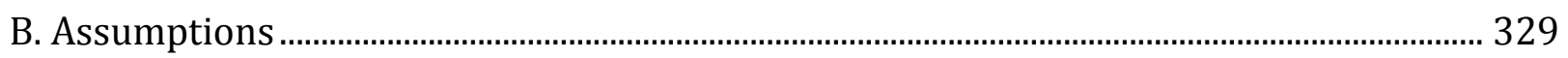

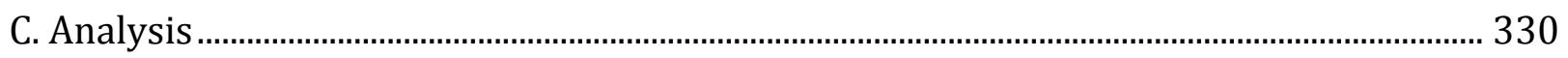

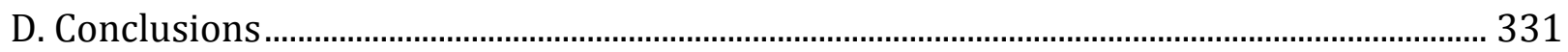

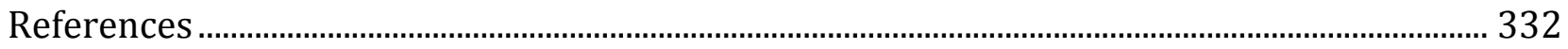




\section{Restatement of the Problem}

The problem asks us to do the following:

- Develop and test a mathematical model that accurately calculates the percentage of American drivers in categories - low, medium, and high — for both hours driven per day and miles driven per day.

- Predict the expected participation in each of four business models in four different cities.

- Take into account the coming emergence of innovative technologies and energy systems to re-rank the four cities in terms of expected participation.

\section{Part I: Who's Riding?}

\section{A. Restatement of the Problem}

In order to truly understand customer profile and demographics, one needs to be aware of two important factors - the average number of hours a driver drives per day and the average distance he/she travels in a day. This critical problem for car-sharing companies becomes more intricate when one realizes that those factors vary based on aspects of the setting, especially population density, as it gives a good idea of the amount of traffic in the area at any given time.

\section{B. Assumptions}

1) With regard to miles driven per day, we define "low," "medium," and "high" to constitute 0-20 miles/day, 20-40 miles/day, and 40+ miles/day, respectively. Using a 2009 dataset from the National Household Travel Survey (NHTS), we derived that 20 miles/day and 40 miles/day were roughly around the $33^{\text {rd }}$ percentile and $67^{\text {th }}$ percentile, respectively, of American drivers' average daily distances.

2) When one is "using" a car, one is actually driving the car.

3) The average driving speed of a car in the U.S. is $30.99 \mathrm{mph}$. This value was derived from NHTS data regarding the average miles per trip and average time per trip.

4) Traffic in a certain city, region, or locale can be considered as standardized over time in a day. This is a reasonable assumption because although traffic often varies in areas due to spontaneous incidents (e.g. car accidents, weather), it does follow a general trend over the course of the day.

5) Cities are uniformly distributed in terms of population. This assumption allows us to ignore differences in traffic and other conditions throughout the city, which makes application of the model possible on a large scale.

6) Across the U.S., the distribution of the amount of time individuals spend on the road is uniform. Though people may live in different regions with different population densities, they will work to minimize travel time. People living in communities with low population densities will tend to drive farther distances but will spend the same amount of time in transit as those in denser areas. 


\section{Developing the Model}

The percentages we obtain depend extensively on our assignments of values to the arbitrary characterizations provided by the problem. More specifically, we need to define what "low," "medium," and "high" mean in the context of miles driven per day and hours traveled per day. Through one of our assumptions, we define "low," "medium," and "high" to mean 0-20 miles/day, 20-40 miles/day, and 40+ miles/day, respectively. For the hours/day factor, we took the dataset from the 2009 NHTS study (sample size of 235,333 individuals) and found the $1^{\text {st }}$ and $3^{\text {rd }}$ quartiles for American drivers' average daily travel times (NHTS). These values were 34 minutes and 111 minutes, respectively.

Since we are trying to find the proportion of individuals who fit each of the 9 categories formed by the combination of the two areas of classification, we need to determine a relationship between $M$, the number of miles one drives per day, and $H$, the number of hours one spends in the car per day. We cannot assume independence, as these two variables are clearly interdependent. Dimensional analysis yields the formula:

$$
M=H v
$$

where $v$ refers to the average velocity of the driver's car. Hence, most of the difficulty comes with understanding how to model the average velocity of the car, as one has to take into account a variety of factors to develop an accurate prediction.

Above all other factors, the most prominent influence on velocity during the trip is the amount of traffic present. Since we assume that traffic in a location is standardized over time, we can view traffic as dependent upon the general amount of activity in an area, which can be simplified to population density. Ideally, when there is no activity taking place (i.e. population density $=0$ ), one travels slightly above the average driving speed, and as the amount of activity increases (i.e. population density increases) without bound, one's average travel speed reaches an asymptotically bounded minimum. Given our assumption that the average driving speed of a car is $30.99 \mathrm{mph}$, we can define $v$ as:

$$
v=(1-T) V_{0}
$$

where $V_{0}$ refers to the average driving speed, $30.99 \mathrm{mph} . T$ is the traffic factor and is equal to:

$$
T(p)=K-e^{-r p}
$$

where $p$ is equal to the population density of the area and $r$ and $K$ are positive constants less than 1. Therefore:

$$
M=H\left(1-K+e^{-r p}\right) V_{0}
$$

If the population density is 0 , then $(1-T) V_{0}$ is greater than $V_{0}$. This is a valid result, since in the absence of traffic (e.g. a very sparsely populated and rural environment), drivers will go faster 
than the average speed (which takes into account increased stopping times and greater periods of driving slow due to immediate traffic and lane switching, among other aspects of driving on a road occupied by other cars). Meanwhile, if the population density is very high, $e^{-r p}$ is approximately 0 , and the $(1-T) V_{0}$ approaches a minimum speed, which makes sense considering that after a certain threshold, increasing the traffic would not significantly slow down vehicles.

Moreover, because drivers in all cities/regions will not all move the same distance in the same time period, we need a distribution of values of distances traveled over the time $H$. Because the number of cars moving in a given region will be large, and because some drivers will go farther than the expected value while others proceed less (potentially as a result of random occurrences like stop signs, traffic lights, accidents, etc.), which implies symmetry, we have the necessary conditions to use a normal distribution to represent the distances drivers travel over the time $H$.

In order to complete our function, we need to find the values of the constants $K$ and $r$. We can do this via curve fitting with data relating to average driving speed, $V_{C}$, in various American cities (Kleint). Using the population densities of these cities and the fact that $T=\frac{V_{0}-V_{C}}{V_{0}}$, we can approximate a good curve that generally captures a wide range of cities' conditions.

\begin{tabular}{|l|l|l|}
\hline City & Population Density $\left(\mathrm{ppl} / \mathrm{mi}^{2}\right)$ & $\mathrm{V}_{\mathrm{C}}(\mathrm{mph})$ \\
\hline Albuquerque, NM & 2908 & 31.2 \\
\hline Dallas, TX & 3518 & 26.1 \\
\hline Washington, D.C. & 9856 & 19.3 \\
\hline Seattle, Washington & 7251 & 24.0 \\
\hline San Diego, California & 4003 & 31.0 \\
\hline
\end{tabular}

Table 1.1 - Sample of the city average driving speed vs. population density data (Kleint).

Using curve-fitting techniques, we can derive a function of the form $K-e^{-r p}$, with $K$ equal to 0.7 and $r$ equal to 0.00009 .

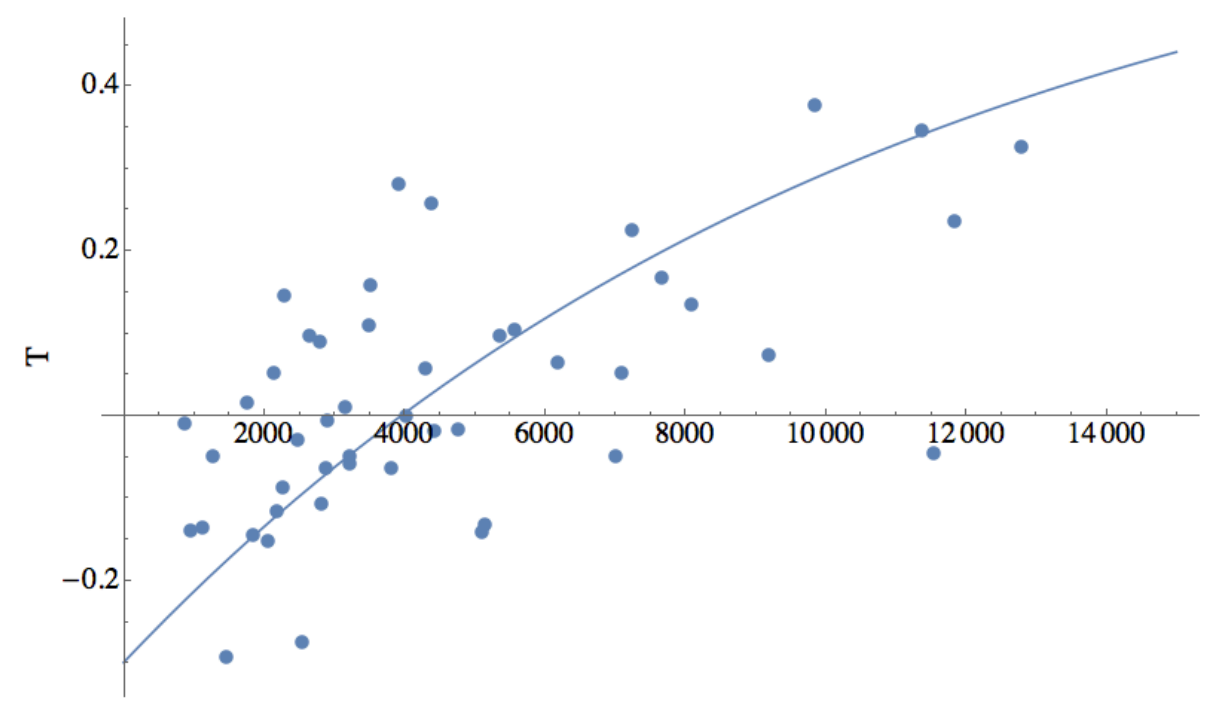

Pop Density $\left(\mathrm{Ppl} / \mathrm{Mi}^{2}\right)$

Figure 1.1 - Plot of the curve fit for $T(p)$ along with the raw data for T vs. Population Density. 
Accordingly:

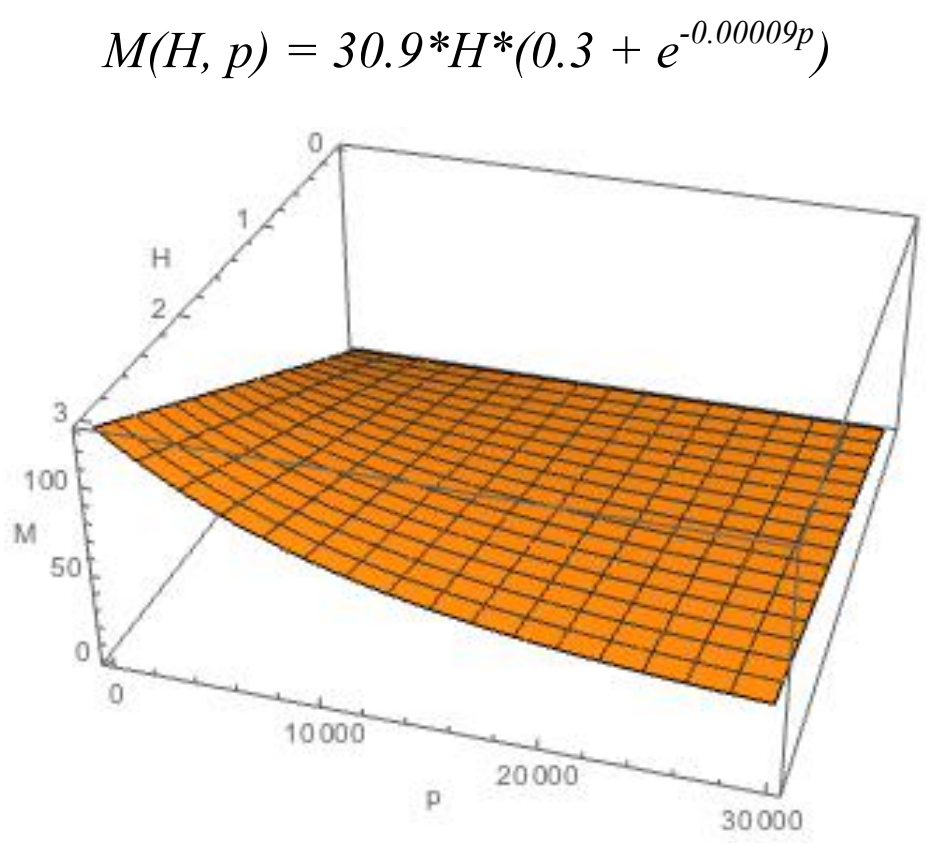

Figure 1.2-3D plot of miles driven per day as a function of population density and hours driven per day.

Our function for $M$ provides us with an expected outcome for the number of miles one would travel in a particular region in a given time period.

In order to model a distribution, we need a standard deviation. The nationwide standard deviation for miles traveled per hour is 5.2645, and the average driving speed is $30.99 \mathrm{mph}$ (NHTS). We can scale this standard deviation value up or down to the level of a specific region's traffic based on the proportion of the city's average speed to the national average driving speed. We obtain the city's average speed by inputting 60 minutes for $H$ in the function for $M$. Based on this knowledge, we can form our normal distribution in the following manner:

$$
G(x, t)=e^{-\frac{\left(x-\frac{t}{60} b\right)^{2}}{2\left(\frac{t}{60} c\right)^{2}}}
$$

where $b$ is equal to the expected average speed returned by our function for $M$ and $c$ is equal to the average standard deviation nationwide scaled to the specific region. Therefore, $(t / 60) * b$ refers to the expected number of miles traveled in a given number of minutes while $(t / 60){ }^{*} c$ refers to the standard deviation of a distribution of those miles traveled. Based on this, the proportion of vehicles traveling more than $y$ miles in a given time period is given by:

$$
1-\int_{t_{\text {initial }}}^{t_{\text {final }}} \operatorname{CDF}[G(x, t), y] d t
$$

where CDF refers to the cumulative distribution function (the probability that $x$ will have a value less than or equal to $y$ ). However, the number of people who travel for 35 minutes on an average 
day likely will not be the same as the number of people who travel for 3 hours on average. Therefore, we are going to need a weighting factor for periods of travel time that is based on the relative frequency of those travel times. In order to determine the distribution of travel times, we look at the aforementioned 2009 NHTS survey that provides American drivers' average daily travel times (NHTS).

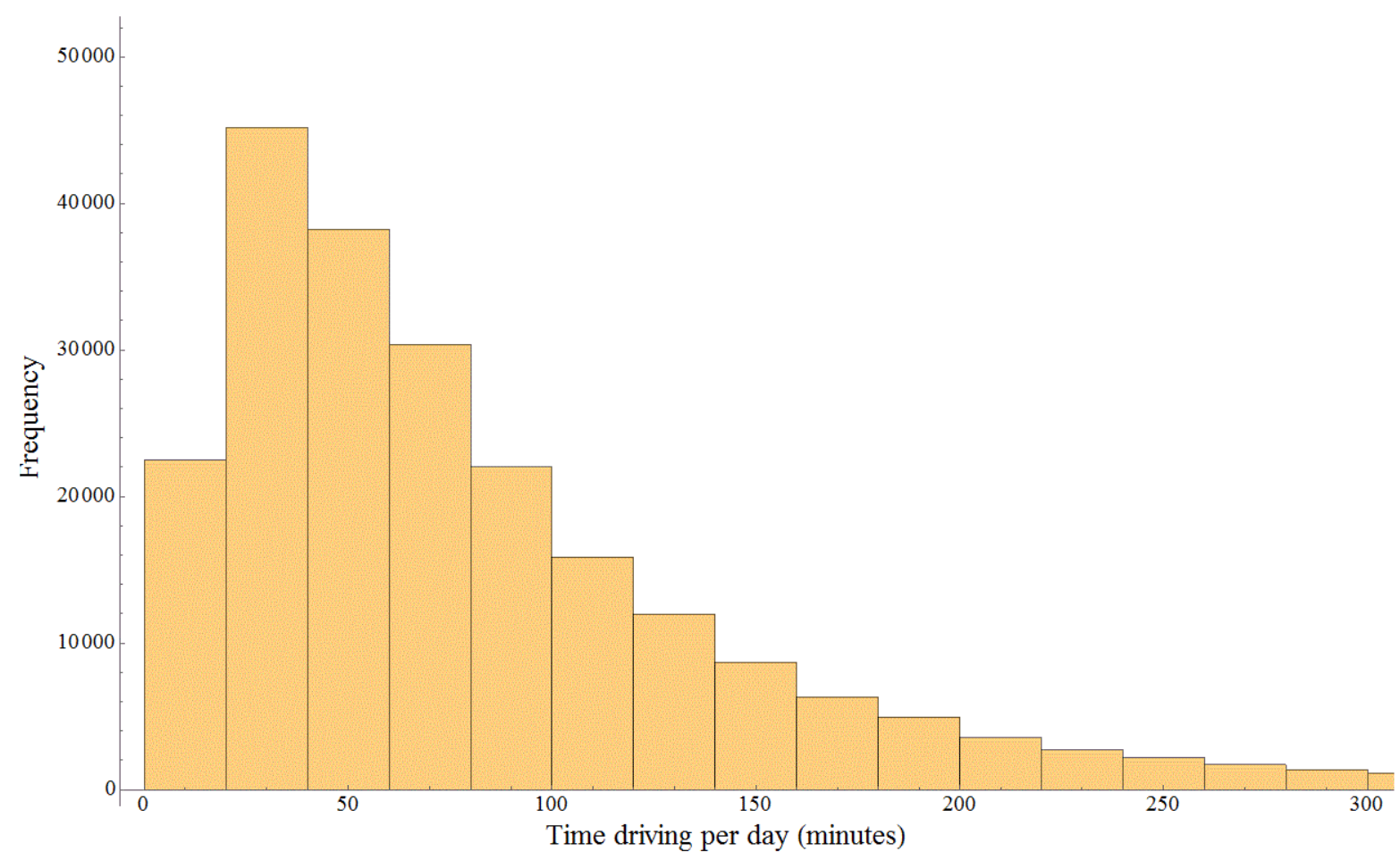

Figure 1.3 - Histogram of the NHTS travel time data.

This dataset allows us to derive a cumulative distribution function that provides us with the proportion of a population (based on our assumption that all Americans share the same daily travel times) that spends under $x$ hours driving per day. The CDF is given and plotted below.

$$
W(x)=C D F[\text { dist }, x]
$$

where the variable dist refers to the distribution of data shown in Figure 1.3. 


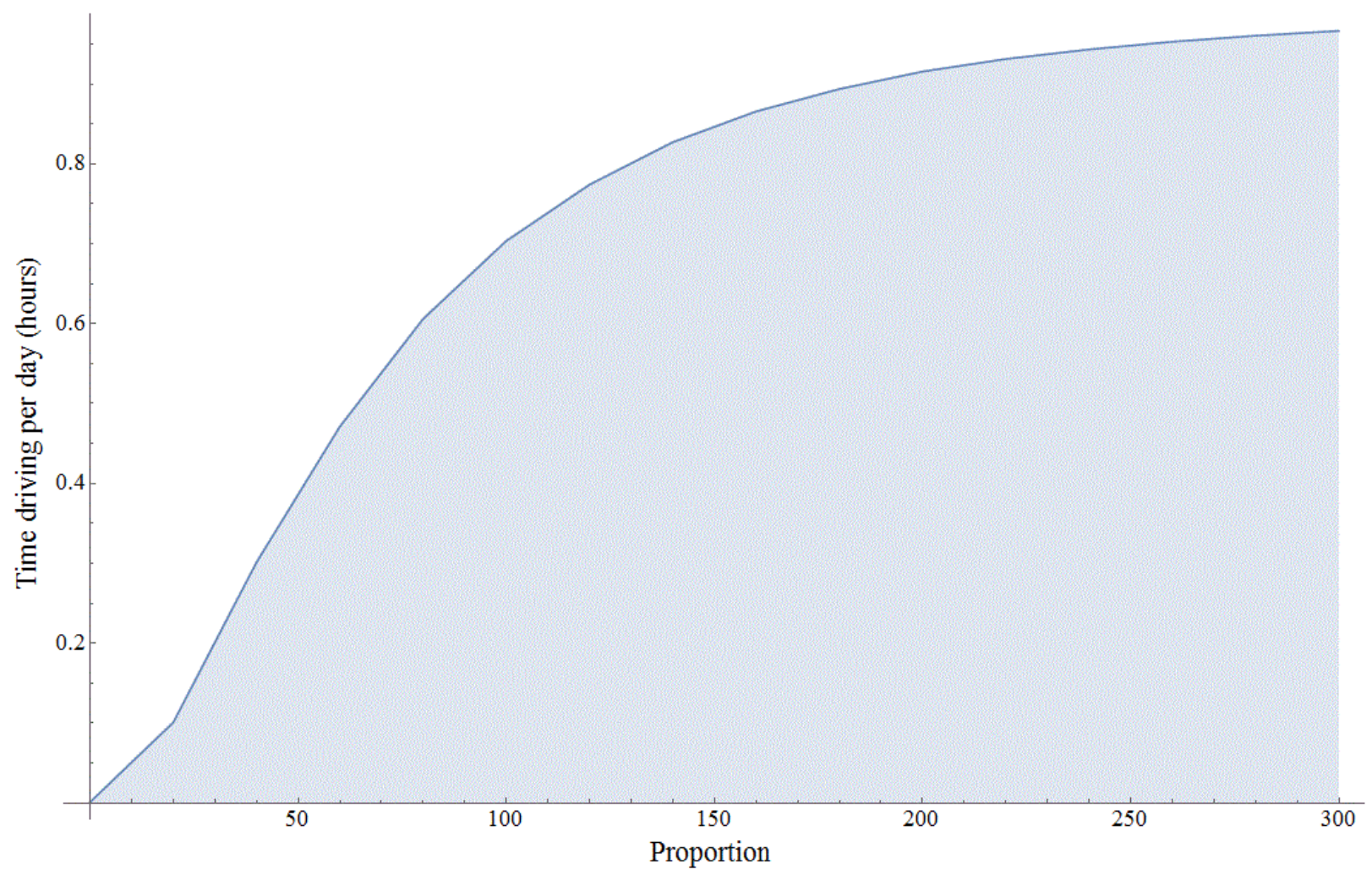

Figure 1.4 - Plot of the CDF, which gives the proportion of drivers who spend $x$ hours or less driving.

The CDF can be used as our weighting factor because it gives us the relative frequencies of various travel times. As a result, we can use the following term to express the relative frequency (and, therefore, weight) of a certain period of travel time between $t_{1}$ minutes and $t_{1}+1$ minutes:

$$
C D F\left[\text { dist }, t_{1}+1\right]-C D F\left[\text { dist }, t_{1}\right]
$$

Thus, we can derive the final function that provides us with the percentage of current U.S. drivers in each category-low, medium, and high-for all combinations of the two specified factors, daily travel time and daily mileage:

$$
1-\int_{t_{\text {initial }}}^{t_{\text {final }}}(C D F[\text { dist }, t+1]-C D F[\text { dist }, t]) \operatorname{CDF}[G(x, t), y] d t
$$

The amount of travel time we wish to check relative proportions for is given by $t$, and the distance we want to see if our population crossed (e.g. 20 miles, 40 miles) is given by $y$.

\section{Validation of the Model}

While developing the model for $T(p)$, we calculated our root mean square error, which came out to be 0.167451 . Given the large variance within the data points, however, this value is 
acceptable, as no population density model can effectively account for all of the variance in the data without resorting to a curve fit that cannot be extrapolated accurately. Hence, the fit function for $T(p)$ does a relatively good job at approximating the trends in the data.

In order to further validate the accuracy of the model, we conducted a sensitivity analysis. Because only two constants were solved for in the model ( $K$ and $r$ ), we decided to vary $K$ and observe the changes in the value of $M(1,2000)$, representing the number of miles per day given that the driver drives for 1 hour in a region with a population density of 2000 people per square mile. Table 1.2 displays the results.

\begin{tabular}{|l|l|l|l|}
\hline $\mathbf{K}$ & $\begin{array}{l}\text { \% Difference from } \\
\text { K= 0.7 }\end{array}$ & $\mathbf{M}(\mathbf{1 , 2 0 0 0})$ & $\begin{array}{l}\text { \% Difference from } \\
\mathbf{M}(\mathbf{1}, \mathbf{2 0 0 0}) \text { with } \mathbf{K}= \\
\mathbf{0 . 7}\end{array}$ \\
\hline 0.8 & 14.29 & 31.9898 & 8.81 \\
\hline 0.75 & 7.14 & 33.5348 & 4.40 \\
\hline 0.7 & 0 & 35.0798 & 0 \\
\hline 0.65 & 7.14 & 36.6248 & 4.40 \\
\hline 0.6 & 14.29 & 38.1698 & 8.81 \\
\hline
\end{tabular}

Table 1.2 - Sensitivity analysis with respect to $K$.

The sensitivity testing reveals that changes in $K$ correspond to about half as significant a change in the output of $M$. This shows that the model is robust and not very sensitive to changes in $K$.

\section{E. Results of the Model}

We used our model to calculate the percentage of drivers in each category of mileage and driving time in New York City, which has a population density of 26,403 people per square mile. Using the integral given at the end of section $\mathrm{B}$, we obtained the following output values.

\begin{tabular}{|l|l|l|l|}
\hline & $\begin{array}{l}\text { Low Driving Time } \\
(<34 \mathrm{~min} / \text { day })\end{array}$ & $\begin{array}{l}\text { Medium Driving Time } \\
(34-111 \mathrm{~min} / \text { day })\end{array}$ & $\begin{array}{l}\text { High Driving Time }(> \\
111 \mathrm{~min} / \mathrm{day})\end{array}$ \\
\hline $\begin{array}{l}\text { Low Mileage }(<20 \\
\text { miles/day) }\end{array}$ & $24.20 \%$ & $35.56 \%$ & $0.17 \%$ \\
\hline $\begin{array}{l}\text { Medium Mileage }(20- \\
40 \text { miles/day) }\end{array}$ & $0 \%$ & $14.20 \%$ & $11.51 \%$ \\
\hline $\begin{array}{l}\text { High Mileage }(>40 \\
\text { miles/day) }\end{array}$ & $0 \%$ & $0.0098 \%$ & $13.90 \%$ \\
\hline
\end{tabular}

Table 1.3 - Results for New York City.

Next, we used our model to determine the various proportions in a sparser suburb: Englewood Cliffs, New Jersey, a small town with a population density of 2506 people per square mile.

\begin{tabular}{|l|l|l|l|}
\hline & $\begin{array}{l}\text { Low Driving Time } \\
(<34 \mathrm{~min} / \text { day })\end{array}$ & $\begin{array}{l}\text { Medium Driving Time } \\
(34-111 \mathrm{~min} / \text { day })\end{array}$ & $\begin{array}{l}\text { High Driving Time }(> \\
111 \mathrm{~min} / \mathrm{day})\end{array}$ \\
\hline $\begin{array}{l}\text { Low Mileage }(<20 \\
\text { miles/day })\end{array}$ & $21.51 \%$ & $2.03 \%$ & $7.79 \mathrm{E}-5 \%$ \\
\hline
\end{tabular}


Team \#6811

\begin{tabular}{|l|l|l|l|}
\hline $\begin{array}{l}\text { Medium Mileage (20- } \\
40 \text { miles/day) }\end{array}$ & $2.69 \%$ & $24.86 \%$ & $0.028 \%$ \\
\hline $\begin{array}{l}\text { High Mileage }(>40 \\
\text { miles/day) }\end{array}$ & $2.43 \mathrm{E}-8 \%$ & $22.88 \%$ & $25.55 \%$ \\
\hline
\end{tabular}

Table 1.4 - Results for Englewood Cliffs.

The analysis of the results reveals the logical nature of the model. In a big city with a high population density, a large proportion of cars travel a low mileage, regardless of the amount of time they spend on the road. $59.93 \%$ of cars travel less than 20 miles, which is sensible given that heavy traffic limits much of the progress those vehicles can make. As a result, big cities tend to have a lot of cars traveling a low number of miles per day, with a very small percentage of cars traveling more than 40 miles.

Meanwhile, in a suburban area such as Englewood Cliffs, more cars travel a high number of miles per day because of the reduced traffic in the region. Though some cars do travel a low number of miles, the proportion of cars that travel more than 40 miles is certainly higher in Englewood Cliffs than in New York City.

\section{F. Strengths and Weaknesses}

While our curve fit rather accurately describes the average speed of cars in New York City (our regression indicates a speed of $15.73 \mathrm{mph}$ compared to a calculated average speed of $17.6 \mathrm{mph}$ ) (Kleint), it is not a perfect model of average car speed vs. population density, for it has an RMSE of 0.1675 . The reasons for this error were addressed earlier, but it remains a fly in the ointment in our model.

However, our model takes into account population density as the major factor in traffic and car speed. In addition, our model is highly intuitive as denser cities tend to have greater traffic and lower speeds. Moreover, our model is adaptable to many different urban or rural landscapes. We have gathered relevant and accurate data for both urban and suburban areas with our model. Furthermore, even though we did not calculate proportions for American drivers as a whole, our model can be applied to any individual setting in America and is therefore much more specific and powerful in the context of realistic applications by car-sharing companies.

\section{G. Summary}

Simple dimensional analysis leads us to understand that the average number of miles driven is a product of average velocity and hours driven per day. Since each region's average velocity depends directly on its traffic, which is dependent upon its population density, we can state the expected miles driven as a function dependent on population density and hours driven in a day. In order to form a distribution around the expected value for miles driven that this function delivers, we can use the nationwide average standard deviation of velocity scaled down from the average nationwide driving speed to the driving speed in the particular city or region being examined to produce a normal distribution. Integrating a cumulative distribution function of this normal distribution, along with the weighting of the relative frequencies of different travel times through another cumulative distribution function, allows us to calculate the proportions of a 
population in each category-low, medium, and high - for all combinations of the two specified factors, hours driven per day and miles driven per day. The results of our model show that less dense regions and cities have a greater proportion of cars traveling higher numbers of miles per day, while denser cities and areas have a higher percentage of cars traveling a smaller number.

\section{Part II: Zippity Do or Don't?}

\section{A. Restatement of the Problem}

A car-sharing transportation method can be defined as any form of transportation involving privately owned vehicles that does not involve a single owner of a vehicle. Car-sharing can help people avoid the costs of owning a vehicle, including insurance, maintenance, and gas. Alternately, car-sharing can be seen as a step up in luxury compared to public transportation; having the privacy of one's own car is seen as favorable to dealing with the chaos of a subway, train, or bus system. Today, roughly $10 \%$ of people choose a shared commuter experience over vehicle ownership (Automotive IQ).

As more people choose car-sharing options over privately owned vehicles, car companies lose vehicle sales. In America, one study estimates that 1.2 million vehicle sales could be lost by 2020 (Automotive IQ). In light of this, many car manufacturers, including Audi, Daimler, GM, and BMW have ventured into the business of car-sharing. As companies attempt to implement car-sharing programs, it is important to consider which car-sharing options will work best for various locations.

There are several viable car-sharing programs in use today. The classic car rental model, popular for decades with travelers flying into airports, involves a "round-trip" rental, in which the consumer rents a vehicle from a location for a certain amount of time and returns the vehicle to the same location. The pricing can be per hour, day, mile, or a combination of the three. Another, newer car-sharing program involves one-way trips. In the one-way floating system, a user picks up a car and can park it anywhere within a certain zone. The one-way station method is similar, but the user must drive the car to a specific station run by the same car-sharing company. Finally, in a more literal interpretation of "car-sharing," multiple people can jointly own a vehicle and share its costs while using it like a privately owned vehicle.

\section{B. Assumptions}

1) The companies do not encounter implementation issues (e.g. implementation or construction costs or malfunctions). These are not within the problem parameters.

2) People are willing to walk or bike half a mile to reach a car-sharing station. Even sedentary people walk 1000-3000 steps a day, and one mile is approximately 2000 steps. Therefore, most healthy people would have no problem walking up to half a mile to reach a transportation station (The Walking Site).

3) Weather is not a factor. Weather varies throughout the year and on a day-to-day basis is essentially random. Weather hazards will impede any sort of transportation and do not impact car-sharing transportation significantly more than other transportation methods. 
4) Users do not drive one-way between cities. In order to analyze one-way car-sharing models for a particular city, the city itself should be isolated with respect to other carsharing cities.

5) Users do not have car crashes, lose insurance documents or keys, park in unauthorized locations, drive without a license, or drive with impaired senses and functionality. In these instances, the cost for any given model skyrockets, and these data points become outliers.

6) Within the central area of a city, the population is uniformly distributed. We assume that the car-sharing company would put their stations in ideal locations, but between two cities the idealness of various locations would differ, on average, by a factor of the average population density for the major metropolitan area.

7) Across cities, bus fares are constant. We researched bus fares for each of the four cities we are investigating. The differences between cities are negligible in our calculations, so for the sake of simplicity, we will assume they are constant.

\section{Modeling the Consumer}

We decided that individual feasibility can be measured in terms of user price $U P$, which is a sum of opportunity cost and monetary cost. Opportunity cost is the amount of time $T$ spent in commute, weighted by individual salary $S$. Monetary cost $M$ is the cost of a certain means of transportation.

$$
U P=T * S+M
$$

We assume that the user wishes to save time and money, and that time saved is more valuable if the user makes a high hourly wage, while money saved is more valuable if the user makes a low hourly wage.

We decided that a user could fall generally into one of four transportation-needing scenarios.

Scenario I: A user needs a vehicle for only one continuous week a year, but has the vehicle 24/7 during that week. For example, this might be a user who uses public transportation within his or her city but takes a week off per year to go on a road trip. Users in this general scenario would live in cities with very good public transportation. We will consider this scenario to be 4 one-way trips, for the sake of comparison.

Scenario II: A user needs a vehicle for only one continuous 3-hour period once a week. For example, this might be a user who uses public transportation for daily commute but needs a vehicle to carry groceries and other goods home once a week. Users in this general scenario would also have good public transportation in their cities. We will consider this scenario to be 4 one-way trips, for the sake of comparison.

Scenario III: A user needs twelve 25-minute rides per week. This user might be someone who commutes to his or her day job every day and works for about eight hours, but also has a weekend excursion of about five hours. We will consider the weekend excursion to be 2 one-way trips, for the sake of comparison. 
Scenario IV: A user needs two 25-minute rides per week. The user would stay at his or her destination for about five hours. This might be someone who uses public transportation to get to work each day but takes a weekend excursion via a car-sharing option.

To model consumer cost of various car-sharing methods for each scenario, we looked at the pricing methods of existing car-sharing companies. For the round-trip program we looked at two companies' pricing models, which differed significantly. Additionally, in the case of joint ownership, we found that maintaining a sedan (including fuel costs) takes $\$ 8,698$ a year, on average. The pricing models are described below:

\begin{tabular}{|l|l|}
\hline Car-sharing method & Pricing method \\
\hline Zipcar Round Trip Monthly & $\begin{array}{l}\text { \$25 initial fee }+\$ 7 \text { per month }+\$ 9.25 \text { per hour or } \$ 84 \text { per } \\
\text { day }\end{array}$ \\
\hline Hertz Round Trip & $\$ 36$ per day \\
\hline One-way floating: Car2go & $\$ 35+\$ 0.41$ per min, \$14.99 per hour, or \$84.99 per day \\
\hline One-way station: Zipcar Boston & $\$ 25$ initial fee $+\$ 7$ per month $+\$ 5$ per 30 min \\
\hline Joint ownership: 2 people & $\$ 4349$ per year \\
\hline Joint ownership: 3 people & $\$ 2900$ per year \\
\hline
\end{tabular}

Applying each of the pricing models to our scenarios, we generated the annual price for each carsharing method.

\begin{tabular}{|l|l|l|l|l|}
\hline & $\begin{array}{l}\text { Scenario I } \\
\text { (\$/year) }\end{array}$ & $\begin{array}{l}\text { Scenario II } \\
\text { (\$/year) }\end{array}$ & $\begin{array}{l}\text { Scenario III } \\
\text { (\$/year) }\end{array}$ & $\begin{array}{l}\text { Scenario IV } \\
\text { (\$/year) }\end{array}$ \\
\hline Round trip Zipcar & 697 & $\mathbf{1 5 5 2}$ & 26083 & 2995 \\
\hline Round trip Hertz & $\mathbf{2 5 2}$ & 1872 & 11232 & 1872 \\
\hline Car2go Floating & 630 & 2373 & 6396 & 1066 \\
\hline Zipcar Boston station & 1705 & 1669 & 3145 & $\mathbf{5 4 5}$ \\
\hline Joint ownership 2 people & 4349 & 4349 & 4349 & 4349 \\
\hline Joint ownership 3 people & 2900 & 2900 & $\mathbf{2 9 0 0}$ & 2900 \\
\hline
\end{tabular}

Table 2.1 - Annual price for each car-sharing method.

In Table 2.1, the bolded values are the most cost-effective option for each scenario. Additionally, an average car commute is 23 minutes and an average bus commute is 53 minutes. The commute time baseline was 25 minutes, so assuming proportionality, the bus commute time would be 58 minutes.

To calculate the time spent in transportation in our user price equations, we assumed that ride sharing is less time-efficient than personally owning a vehicle. If an individual chooses to use a car rental service, he or she must travel (we will assume by foot) to the car rental station before he or she can begin driving. If an individual chooses to jointly own a car with others, the vehicle may not be available at any given time. Thus, we have determined additional times required for each method of car sharing in minutes per one-way trip. 
In determining these values, we assumed the following:

- An individual can walk half a mile in 10 minutes.

- A round-trip Zipcar station will be located at a distance of half a mile from any given location. An individual has to walk half a mile from his/her house to the rental station and 0 miles from the parking spot to the final destination.

- A round-trip Hertz station will be located farther away. Hertz is a less developed carsharing service, so its stations are more spread out. An individual will need 15 minutes rather than 10 to walk to a Hertz station.

- One-way floating rental sites are more abundant throughout the city. Thus, an individual will walk a smaller distance (and for a smaller duration of time) from his or her home to a one-way floating rental site.

- One-way station model rental sites require half a mile of walking from an individual's house to the site, and half a mile of walking from the parking site to the final destination.

- With joint ownership with a second person, there is a 1/10 chance the car will not be readily available for use.

- With a third person, there is a $1 / 8$ chance the car will not be readily available for use.

- Each "trip" taken by one's "car-mate" is assumed to be 2 hours long.

\begin{tabular}{|l|l|}
\hline Car-sharing method & Additional time required per usage (minutes) \\
\hline Round trip Zipcar & 10 \\
\hline Round trip Hertz & 15 \\
\hline One-way floating Car2go & 7 \\
\hline One-way Station Zipcar Boston & 20 \\
\hline Joint ownership 2 people total & 12 \\
\hline Joint ownership 3 people total & 15 \\
\hline
\end{tabular}

Using these assumptions, we calculated the time in minutes spent commuting per year:

\begin{tabular}{|l|l|l|l|l|}
\hline $\begin{array}{l}\text { Transportation } \\
\text { method }\end{array}$ & $\begin{array}{l}\text { Scenario I } \\
(\mathrm{min} / \text { year })\end{array}$ & $\begin{array}{l}\text { Scenario II } \\
(\mathrm{min} / \text { year })\end{array}$ & $\begin{array}{l}\text { Scenario III } \\
(\mathrm{min} / \text { year) }\end{array}$ & $\begin{array}{l}\text { Scenario IV } \\
\text { (min/year) }\end{array}$ \\
\hline Round trip Zipcar & 924 & 6484 & 20592 & 3432 \\
\hline Round trip Hertz & 1064 & 7904 & 23712 & 3952 \\
\hline $\begin{array}{l}\text { One-way floating } \\
\text { Car2go }\end{array}$ & 840 & 6240 & 18720 & 3120 \\
\hline $\begin{array}{l}\text { One-way station } \\
\text { Zipcar Boston }\end{array}$ & 1204 & 8944 & 26832 & 4472 \\
\hline $\begin{array}{l}\text { Joint ownership 2 } \\
\text { people }\end{array}$ & 980 & 7280 & 21840 & 3640 \\
\hline $\begin{array}{l}\text { Joint ownership 3 } \\
\text { people }\end{array}$ & 1316 & 9776 & 29328 & 4888 \\
\hline Individually owned & 644 & 4784 & 14352 & 2392 \\
\hline Public transportation & 1484 & 11024 & 33072 & 5512 \\
\hline
\end{tabular}

Table 2.2-Commuting time per year for each car-sharing method. 
Now, using the user price equation, we plugged in numbers for $T$ and $M$ for each scenario and transportation method. We let $S$ be an independent variable and plotted the relationship between $S$ and $U P$ for each transportation method in each scenario. Therefore, on our plots, a line intersection represents a change in the relative feasibility of two transportation options, and the bottom most line represents the cheapest transportation option. Below are the plots we generated.
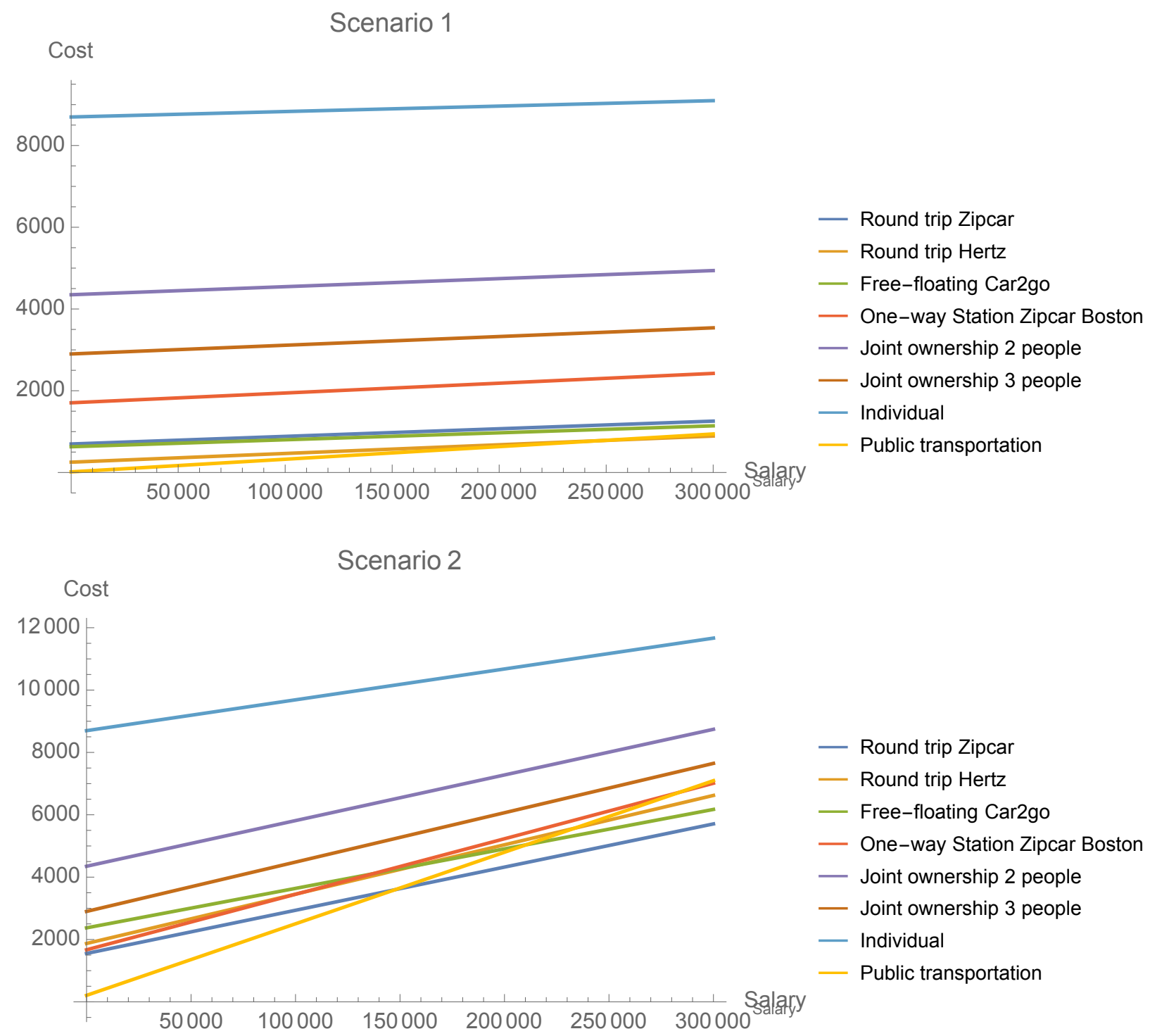


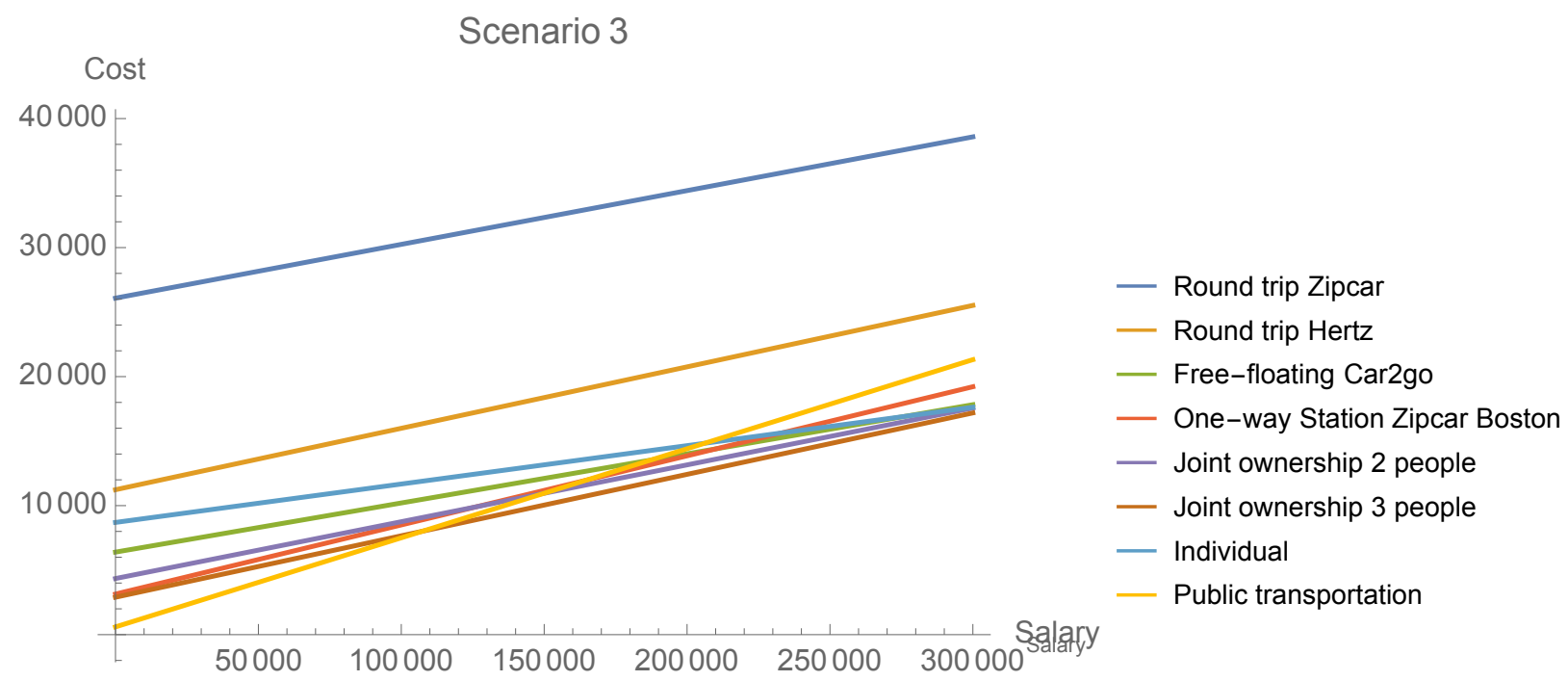

Scenario 4

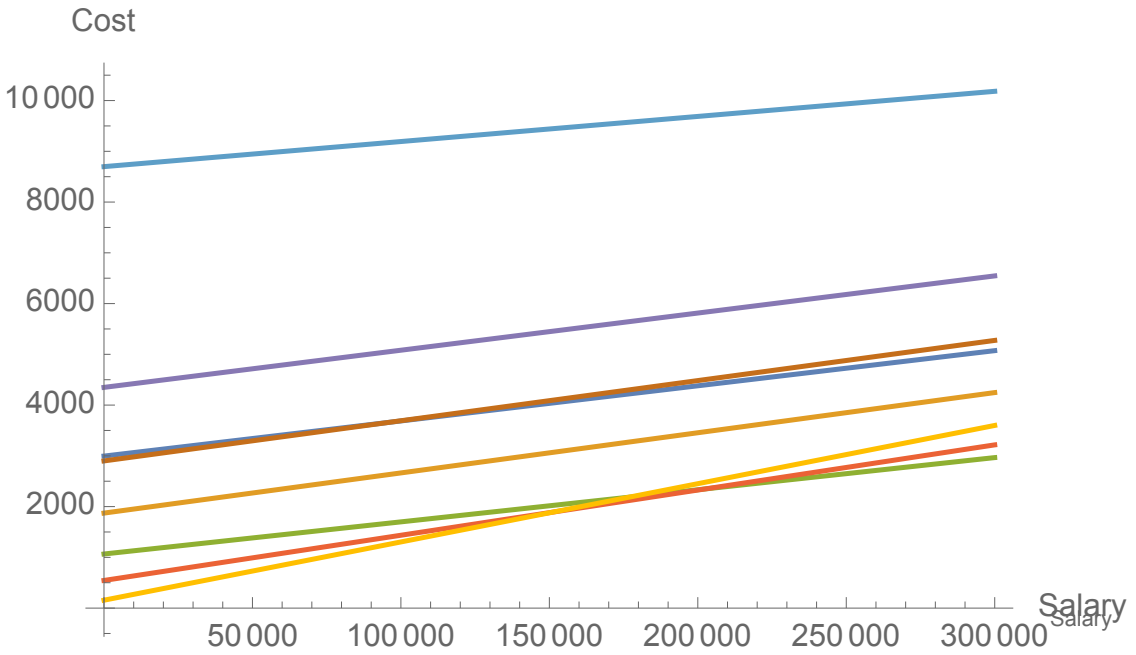

— Round trip Zipcar

- Round trip Hertz

- Free-floating Car2go

- One-way Station Zipcar Boston

— Joint ownership 2 people

— Joint ownership 3 people

- Individual

- Public transportation

At a salary of under $\$ 50,000$, public transportation is by far the best option. Our equation weights commute time with individual salary, so when salary is relatively low (under $\$ 50,000$ ), the predominant factor in determining price $P$ is the monetary cost $M$. As the median per capita salaries of the four cities range from $\$ 21,000$ to $\$ 27,000$, for the average consumer, public transportation is the most advantageous option.

However, as the plots indicate, certain ride-sharing options become much more economically advantageous when individual salaries increase. For Scenario II, as individual salary increases, the most economically advantageous options are individual ownership and one-way floating Car2go. For Scenario III, joint ownership and individual ownership are most advantageous, and for Scenario IV, one-way floating Car2go and one-way Station Zipcar Boston are most advantageous. 


\section{Modeling the Company}

Now that we've analyzed what options are most consumer friendly, we will look at the options from a company's point of view. We decided that company viability can be measured in terms of profit, and the profit a company makes from a car-sharing business in a given region is determined by the equation:

$$
\text { Profit }=(\text { Revenue }- \text { Cost }) * \text { Usage }
$$

where profit, revenue, and cost are all per user, and usage is a function of both population density around a car-sharing station and the feasibility of the car-sharing method for an individual.

Each car-sharing option uses a different pricing model and will generate different revenue per user. In general, pricing models consist of a new user fee, a monthly fee, an hourly fee, or a combination of those fees:

$$
\text { Revenue }=N C * N U+M C * 12+\frac{T U * 24 * 365 * H R}{U P V}
$$

where $N C$ stands for the new user fee, $N U$ is the number of new users, $M C$ is the monthly fee, $T U$ is the percent of time the car is used, $H R$ is the hourly rate, and $U P V$ is the number of users per vehicle. Since the number of car-sharing users has doubled in the past five to six years, using an exponential growth rate we can deduce that the growth rate is $12 \%$. This means that in any given year, about $12 \%$ of users are new.

For the Zipcar round trip model, for example, the average revenue made per user per year is given by:

$$
\$ 25 * \frac{0.12}{\text { user }}+\$ 7 * \frac{12}{\text { user }}+\frac{0.75 * 24 \frac{\text { hours }}{\text { day }} * 365 \frac{\text { days }}{y r} * \frac{\$ 9.25}{\text { hour } / \text { car }}}{90 \text { users } / \text { car }}=\$ 762
$$

We decided that company cost per user was a combination of gas prices and the cost of regular car maintenance:

$$
\text { Cost }=\frac{C M+G * \frac{M P Y}{M P G}}{U P V}
$$

where $C M$ is the cost to maintain a car per year, $\mathrm{G}$ is the cost of one gallon of gas, $M P Y$ is miles driven per year, $M P G$ is the miles per gallon of the car, and $U P V$ is again users per vehicle. From Part I we found that the average miles driven per day are 28.97 miles, which translates to 21148 miles per year. The average miles per gallon of a U.S. car is $25.5 \mathrm{mpg}$ (Automotive News).

We found that Zipcar has a ratio of 90 users per car (Zipcar Wikipedia). We assume that these cars are used $75 \%$ of the time and that gas costs $\$ 1.71$ per gallon (Fuel Gauge Report). On average, we found that it takes $\$ 8698$ a year to maintain a sedan, including fuel. Since Zipcars are used much more frequently than regular cars, however, we will assume that it still costs more 
to maintain these cars, so we estimate $\$ 10,000$ per year (Newsroom). From this we have the equation for Zipcar's cost per user:

$$
\frac{\$ 10,000+\$ 1.71 * \frac{21148 \text { miles per year }}{25.5 \text { miles per gallon }}}{90 \text { members }}=\$ 126.90
$$

Hertz rents cars by day more often, so we can estimate that their cars are rented out more often since they can be rented out even when the user is not driving them. We assume that $85 \%$ of Hertz cars are rented out at any given time. Since in our model Hertz was best for people renting a car full-time for a week, we assume each Hertz user uses the vehicle for one week on average. One-way models probably have to use more cars per user than Zipcar round-trip does because the cars are not all in a central location. For this reason, we will then assume a ratio of 60 users per car in one-way models. Using the pricing models for each car-sharing option, we obtain the following results:

\begin{tabular}{|l|l|l|l|}
\hline Car-sharing method & $\begin{array}{l}\text { Revenue per user } \\
\text { per year }(\$)\end{array}$ & $\begin{array}{l}\text { Cost per user per } \\
\text { year }(\$)\end{array}$ & $\begin{array}{l}\text { (Revenue }- \text { Cost }) \\
\text { per user per year }\end{array}$ \\
\hline Round-trip Zipcar & 762 & 126.9 & 635.1 \\
\hline Round-trip Hertz & 214 & 126.9 & 87.1 \\
\hline One-way floating Car2go & 1641 & 190.4 & 1450.6 \\
\hline One-way Station Zipcar Boston & 675.25 & 190.4 & 484.85 \\
\hline
\end{tabular}

Table 2.3 - Profit per user per year for each car-sharing method.

For the total profit, we need to multiply (Revenue - Cost) per user per year by the number of users. An individual will only be incentivized to switch to car-sharing if car-sharing is the cheapest option, and that will be true only if individual salary exceeds a certain number. And the company will benefit only if it can maximize the number of users as well as minimize the number of rental stations. We are looking for the greatest number of people per unit area with enough money to afford car-sharing. The cities with the greatest population densities, and thus the greatest number of people who can afford car-sharing, are Poughkeepsie, NY (density of $5983 \mathrm{ppl} / \mathrm{mi}^{2}$ ), Richmond, VA (3625 ppl/ $\left.\mathrm{mi}^{2}\right)$, Riverside, CA (3085 ppl/mi ${ }^{2}$ ), and Knoxville, TN (1861 ppl/ $\left.\mathrm{mi}^{2}\right)$.

As median per capita income is relatively low and relatively similar for every city, we assume that each city has the same per capita income distribution. Thus we assume that each city has a proportion $k$ (a very small number) of individuals with the financial means to participate in ridesharing. With this in mind, the total profit of a company will be:

$$
\text { Profit }=(\text { revenue }-\cos t) * \text { users }=(\text { revenue }-\cos t){ }^{*} k^{*} \text { population density }
$$

For each city, the profit, in millions of dollars and in terms of the constant multiplier $\mathrm{k}$, is:

\begin{tabular}{|l|c|c|c|c|}
\hline & $\begin{array}{c}\text { Poughkeepsie, NY } \\
\text { (millions of \$) }\end{array}$ & $\begin{array}{c}\text { Richmond, VA } \\
\text { (millions of \$) }\end{array}$ & $\begin{array}{c}\text { Riverside, CA } \\
\text { (millions of \$) }\end{array}$ & $\begin{array}{c}\text { Knoxville TN } \\
\text { (millions of \$) }\end{array}$ \\
\hline Round-trip Zipcar & $3.80 * \mathrm{k}$ & $2.30 * \mathrm{k}$ & $1.96 * \mathrm{k}$ & $1.18^{*} \mathrm{k}$ \\
\hline
\end{tabular}




\begin{tabular}{|c|c|c|c|c|}
\hline Round-trip Hertz & $0.52 * \mathrm{k}$ & $0.32 * \mathrm{k}$ & $0.27 * \mathrm{k}$ & $0.16 * \mathrm{k}$ \\
\hline One-way floating & $\mathbf{8 . 6 8} * \mathbf{k}$ & $\mathbf{5 . 2 6} * \mathbf{k}$ & $\mathbf{4 . 4 7} * \mathbf{k}$ & $\mathbf{2 . 7 0} * \mathbf{k}$ \\
\hline One-way & $2.90 * \mathrm{k}$ & $1.76 * \mathrm{k}$ & $1.50 * \mathrm{k}$ & $0.90 * \mathrm{k}$ \\
\hline
\end{tabular}

Table 2.4 - Company profit for each city in millions of dollars.

The most profitable options for a car-sharing company are the one-way floating model and the round trip Zipcar model. The most economical option for an individual (with enough salary) is one-way floating Car2go. Ranked from best to worst, the cities for a company to develop carsharing in are: Poughkeepsie, Richmond, Riverside, Knoxville. Thus, our final recommendation is that a car company should invest in developing a one-way floating car-sharing system for the city of Poughkeepsie, NY.

\section{E. Limitations}

We assumed that the per capita incomes of each city were relatively equal because the discrepancies we found were not very significant. To improve on our model, we would take those differences into account by estimating how many individuals would be able to afford carsharing. Even better, if we were able to find a per capita income distribution for each of the cities, we could improve on our model even more by having a more definitive number for individuals able to participate, rather than a rough estimate.

When determining profitability of each model, we did not incorporate the cost of the jockey for the one-way floating Car2go model because we ran out of time. However, given that it was more profitable than the next best option by close to $300 \%$, this additional cost likely would not have made a big difference in the overall profitability of that model.

\section{Part III: Road Map to the Future}

\section{A. Restatement of the Problem}

Alternative energy vehicles and self-driving vehicles have the ability to dramatically alter the car-transportation business. The incredible growth of Uber has demonstrated that by eliminating the hassle of commuting to a car-sharing station without a car, the cost benefits of car-sharing can truly monopolize the market (Los Angeles Times). Self-driving vehicles would allow users to have vehicles delivered directly to their doorstep, replicating the convenience of having a privately owned vehicle. Many people also choose public transportation, biking, or walking over vehicular transport because they want to consume less fuel. For this reason, car-sharing alternative energy vehicles would allow users to be environmentally friendly and take advantage of the convenience of a vehicle.

\section{B. Assumptions}

1) Self-driving vehicles would allow all car-sharing businesses to be one-way because the car could drive itself back to any needed location. Stations would not be required because of the self-driving function, so all options would resemble the one-way floating option. 
2) Users would stay within a certain radius to avoid exorbitant costs of having the car drive itself back between cities.

\section{Analysis}

The self-driving feature would eliminate the cost-opportunity of the time taken to reach a carsharing region. Using the pricing model of the one-way floating model of Car2Go, the selfdriving car option comes out as the best option in both Scenario III and Scenario IV.
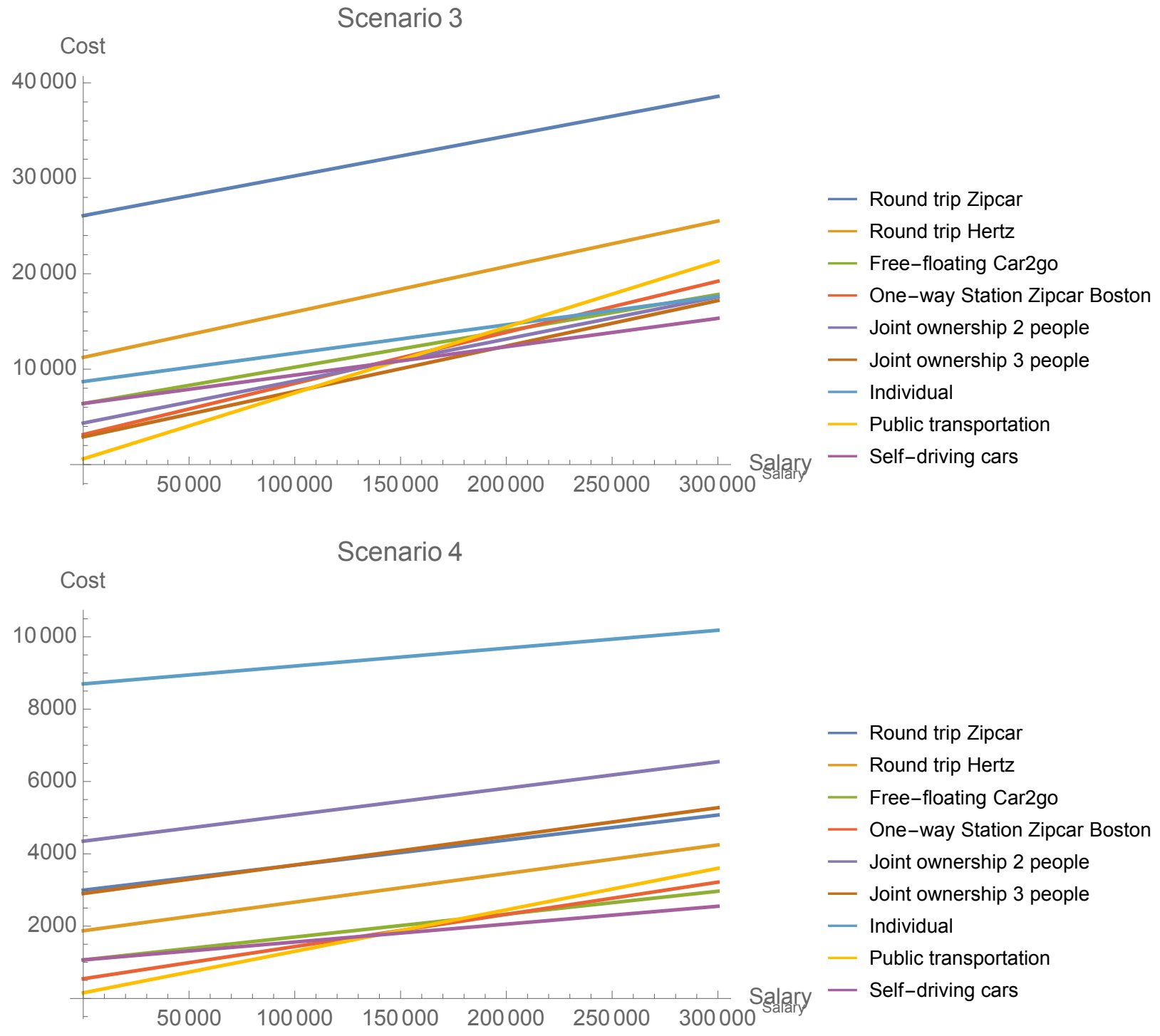

Not only would it increase the benefit for the user in terms of time saved, but it would also benefit the car-sharing company by decreasing fuel cost and by increasing usage due to the environmentally-friendly perk. However, it takes an electric car at minimum four hours to completely recharge and it can only go about 100 miles. Since the average speed we found in Part I was $30.99 \mathrm{mph}$, this means that an electric car must spend about $60 \%$ of its time charging as opposed to being a profitable asset for the company. This lowers the one-way floating model's 
revenue per user, as shown in the chart below. In addition, the cost of charging the car ends up approximately equal to the cost of fuel due to the recent plummet of fuel prices (Forbes).

\begin{tabular}{|l|l|l|l|}
\hline Car-sharing method & $\begin{array}{l}\text { Revenue per user per } \\
\text { year }(\$)\end{array}$ & $\begin{array}{l}\text { Cost per user per } \\
\text { year }(\$)\end{array}$ & $\begin{array}{l}\text { (Revenue }- \text { Cost) per } \\
\text { user per year }(\$)\end{array}$ \\
\hline $\begin{array}{l}\text { One-way floating } \\
\text { Car2go }\end{array}$ & 1641 & 190.4 & 1450.6 \\
\hline Self-driving car & 875.416 & 190.4 & 685 \\
\hline
\end{tabular}

\section{Conclusions}

This model does not take into consideration the fact that self-driving cars and environmentallyfriendly cars are much more expensive than regular sedans. Currently, the price of self-driving cars is far too high for a feasible model. However, once self-driving cars become more commonplace, they will see their usage increase. People without licenses and people who would otherwise not meet the safety requirements for car-sharing companies would suddenly become a target group for marketing. Over time, self-driving cars and energy-efficient vehicles would become more cost-effective, moving them solidly into the limelight of the car-sharing industry. 


\section{References}

"10,000 STEPS A DAY" The Walking Site. The Walking Site, n.d. Web. 28 Feb. 2016.

"A New Way to Zip | Zipcar." A New Way to Zip. Zipcar, n.d. Web. 28 Feb. 2016.

"AAA's Daily Fuel Report." AAA's Daily Fuel Gauge Report. AAA, n.d. Web. 28 Feb. 2016.

"American Driving Survey: Methodology and Year One Results, May 2013 - May 2014." AAA Foundation for Traffic Safety (n.d.): n. pag. Web. 28 Feb. 2016.

"Annual Cost to Own and Operate a Vehicle Falls to \$8,698, Finds AAA | AAA NewsRoom." AAA NewsRoom. AAA, 27 Apr. 2015. Web. 28 Feb. 2016.

"Autonomous Car." Wikipedia. Wikimedia Foundation, n.d. Web. 28 Feb. 2016.

"Average U.S. Mpg Edges up to 25.5 in May." Automotive News. Automotive News, n.d. Web. 28 Feb. 2016.

"Can EVs Handle the Distances We Drive? - A Study." Solar Journey USA. N.p., n.d. Web. 28 Feb. 2016.

"CarSharing: State of the Market and Growth Potential." Auto Rental News. Auto Rental News, n.d. Web. 28 Feb. 2016.

"Compare Plans." Zipcar. Zipcar, n.d. Web. 28 Feb. 2016.

"Country Statistical Profile: United States 2009." Commuting in the United States (2009): n. pag. American Community Survey Reports. ACS. Web. 28 Feb. 2016.

"Drivenow Preise \& Gratis Gutschein." Drivegutschein. Drivegutschein, n.d. Web. 28 Feb. 2016.

"Driver's Seat." Plug in America. Plug in America, n.d. Web. 28 Feb. 2016.

"Ford Is Betting \$4.5 Billion on Radically Transforming the Company and Its Mission."

Business Insider. Business Insider, n.d. Web. 28 Feb. 2016.

"General Motors Is Launching a New Car-Sharing Service." Time. Time, n.d. Web. 28 Feb. 2016.

Kleint, John. "How Fast Is Your City?" How Fast Is Your City? Infinite Monkey Corps, 8 Oct. 2009. Web. 28 Feb. 2016.

"List of US Cities by Population Density." Wikipedia. Wikimedia Foundation, n.d. Web. 28 Feb. 2016.

"New York City." Wikipedia. Wikimedia Foundation, n.d. Web. 28 Feb. 2016.

"One-way Carsharing's Evolution in the Americas." Move Forward. Move Forward, n.d. Web. 28 Feb. 2016.

"Online Analysis Tools." NHTS. NHTS, n.d. Web. 28 Feb. 2016.

"Table Designer." NHTS. NHTS, n.d. Web. 28 Feb. 2016.

"The Impact of Car Sharing on the World As We Know It." Automotive IQ. Automotive IQ, n.d. Web. 28 Feb. 2016.

"Uber Is on Growth Fast Track, Leaked Document Shows." Los Angeles Times. Los Angeles Times, n.d. Web. 28 Feb. 2016.

"Vehicle Guide." Hertz. Hertz, n.d. Web. 28 Feb. 2016.

"Will Low Gasoline Prices Whipsaw The Auto Industry Again?" Forbes. Forbes Magazine, n.d. Web. 28 Feb. 2016.

"ZipCar vs. Hertz Rental Car Comparison - Consumer Reports News."ConsumerReports. Consumer Reports, n.d. Web. 28 Feb. 2016.

"Zipcar, Google and Why the Carsharing Wars Are Just Beginning."GreenBiz. GreenBiz, n.d. Web. 28 Feb. 2016. 